\title{
THE ECONOMIC IMPACT OF SCHIZOPHRENIA IN ROMANIAN PSYCHIATRIC PATIENTS
}

\section{Saftencu ${ }^{1}, \underline{\text { C. Crișan }}{ }^{*}$, I. Micluția ${ }^{2}$}

1"Iuliu Hațieganu" University of Medicine and Pharmacy, Faculty of Medicine, Cluj-Napoca, Romania

2"Iuliu Hațieganu" University of Medicine and Pharmacy, Department of Neurosciences, Discipline of Psychiatry and Pediatric Psychiatry Cluj-Napoca, Romania

\section{BACKGROUND AND AIMS}

Mental health care usually demands an association between hospitalization, outpatient treatment and medication.

Schizophrenia is a serious psychiatric condition and it is oftenly seen as an important clinical, social and economic burden on individuals suffering from it, their families and the whole society. The aim of our study was to evaluate the costs associated to psychiatric care in patients admitted to the Psychiatry Department of the Emergency County Hospital Cluj-Napoca and diagnosed with schizophrenia.

\section{METHODS}

We performed a retrospective analysis of the patients admitted in 2017 and diagnosed with schizophrenia, applying several inclusion and exclusion criteria (Fig. 1).

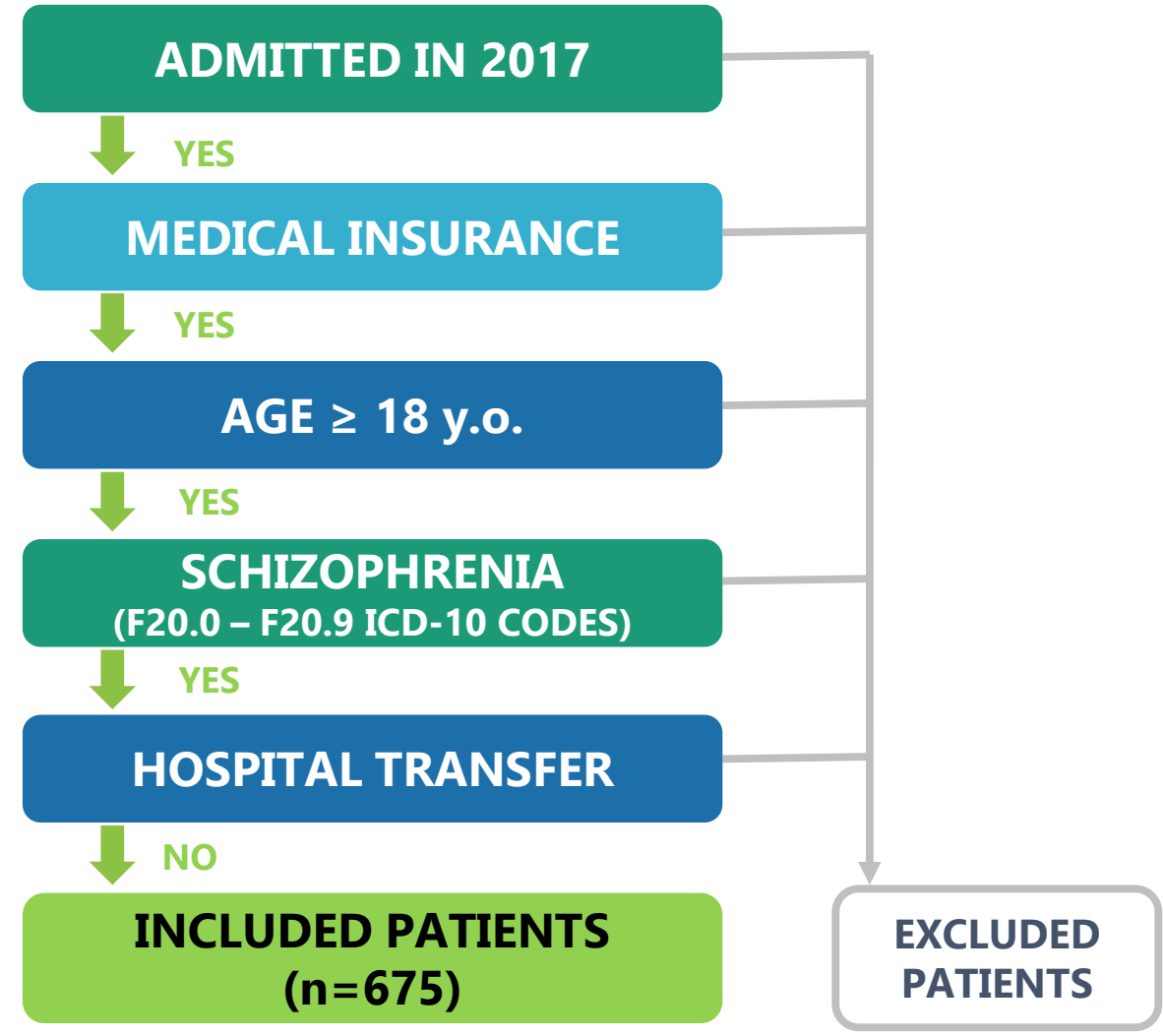

Fig. 1 - Inclusion and exclusion criteria for our study

\section{RESULTS}

Out of a total of 3483 admitted patients, $19.3 \%$ were diagnosed with schizophrenia ( $n=675,345$ male patients). The group had a mean age of 41.41 years old $(95 \% \mathrm{Cl} \pm 0.03)$, more than half of patients being younger than 40 years old (Fig. 2).

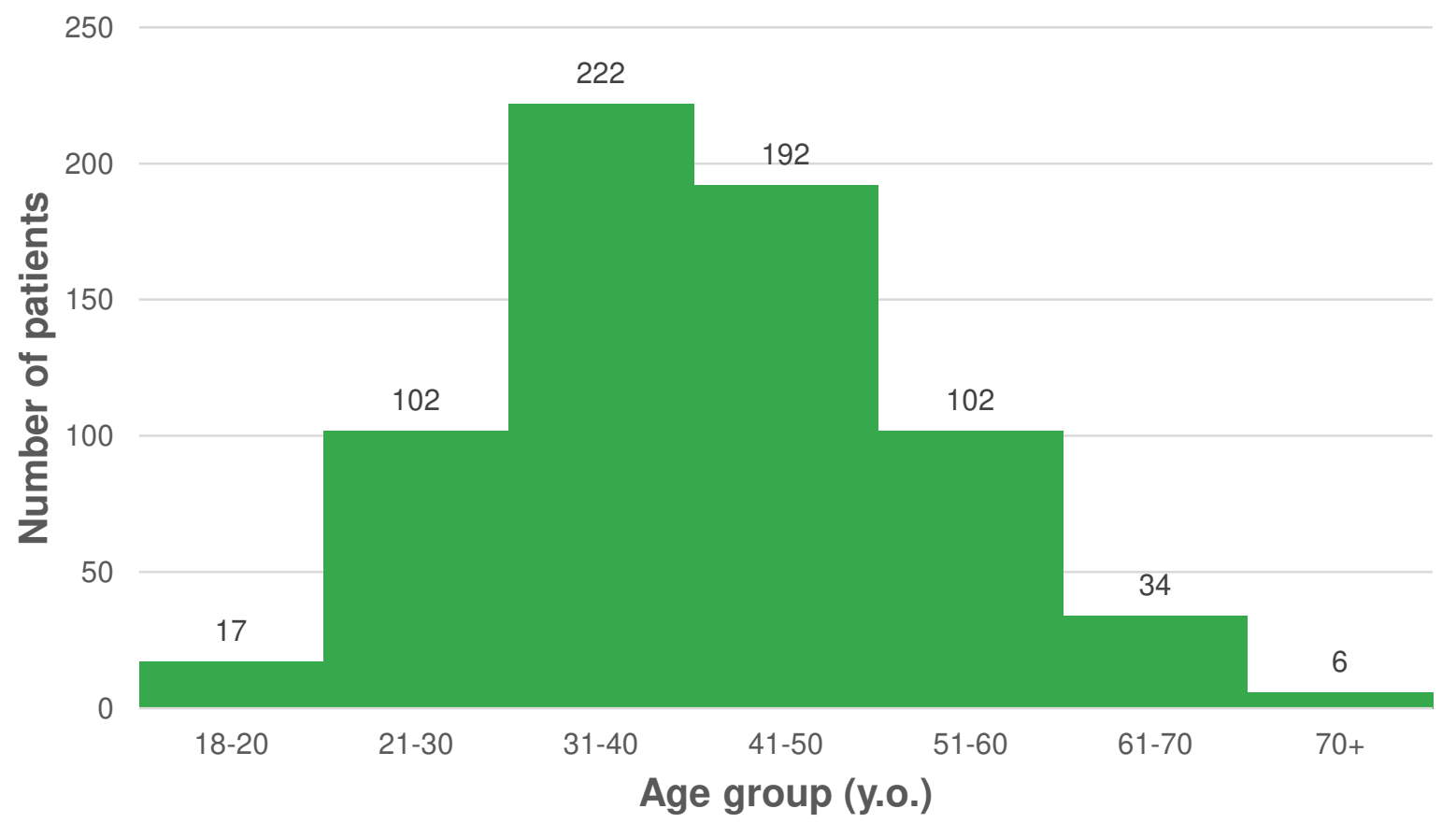

Fig. 2 - Age distribution of schizophrenic patients among our group
The most frequent diagnoses were paranoid schizophrenia (388 patients) and undifferentiated schizophrenia (255 patients). All other ICD-10 diagnostic codes were used on 32 patients (Fig. 3).

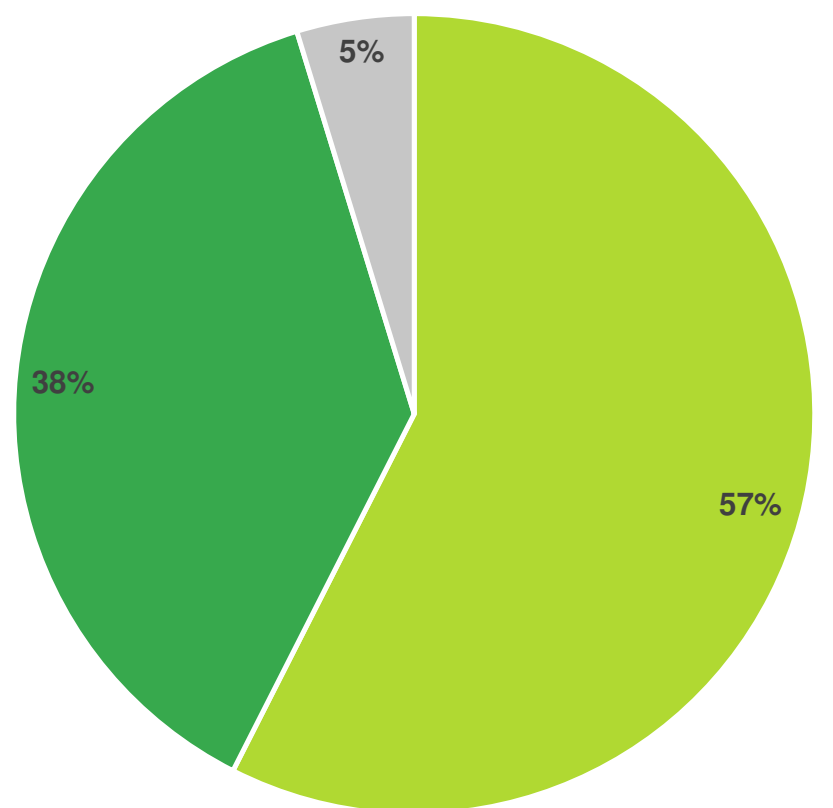

- F20.0 - Paranoid Schizophrenia

- F20.3 - Undifferentiated Schizophrenia

Other types of Schizophrenia

Fig. 3 - Percentual distribution of schizophrenia subtypes Incidence according to ICD-10 diagnostic code among our group

Patients were admitted for an average number of $\mathbf{1 7 . 4 4}$ days/patient $(95 \% \mathrm{Cl} \pm 0.03)$, generating an average cost of 7582 RON/patient (95\% Cl \pm 428), (1660 EUR* (95\% Cl \pm 93$)$ ). Data analysis by gender (Table 1) showed us that men had a significantly higher number of hospitalization days than women $(p=0.01)$, which lead to a significantly higher cost of hospitalization for male patients $(p=0.01)$. Our group generated a total health care cost of $\mathbf{5 . 1 M}$ RON (1.1 M EUR*).

\begin{tabular}{|c|c|c|c|}
\hline & Male & Female & $p$ \\
\hline $\begin{array}{c}\text { Average number of } \\
\text { hospitalization days } \\
(95 \% \mathrm{Cl})\end{array}$ & $\begin{array}{c}18.6 \\
\pm 1.59\end{array}$ & $\begin{array}{r}16.22 \\
\pm 1.13\end{array}$ & 0.01 \\
\hline $\begin{array}{l}\text { Average costs } \\
\text { (RON, } 95 \% \mathrm{Cl} \text { ) }\end{array}$ & $\begin{array}{c}8096.23 \\
\pm 688\end{array}$ & $\begin{array}{c}7044.57 \\
\pm 492\end{array}$ & 0.01 \\
\hline
\end{tabular}

Table 1 - Lenght of hospitalization and costs by gender in schizophrenic patients from our study

\section{CONCLUSIONS}

Schizophrenia has a major economic impact, especially in male patients. Adequate treatments in out-patient clinics and better therapeutic adherence could lead to a decrease of economical burden, to an increased cost-efficiency rate and, finally, to a better patient care.

\section{KEYWORDS}

schizophrenia / psychiatric costs / economic impact cost-efficiency rate / mental health economics
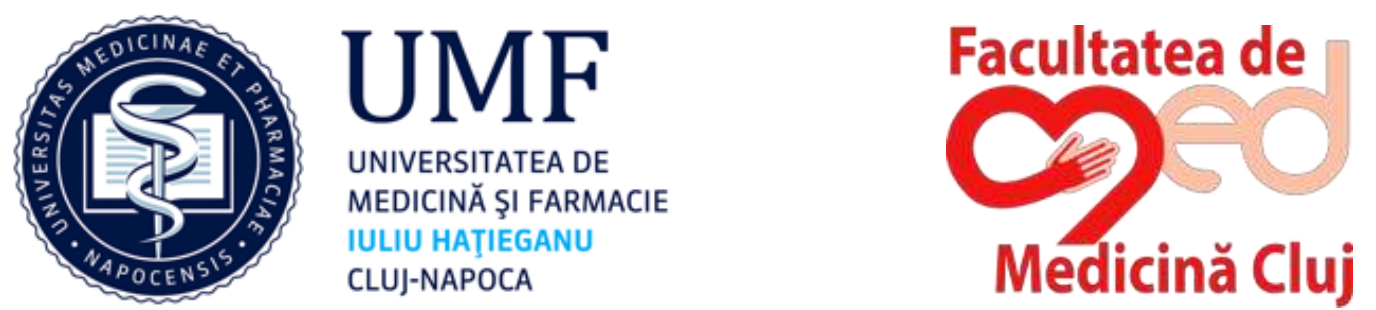

\section{Selective references:}

1. Somaiya M, Grover S, Avasthi A, Chakrabarti S. Changes in cost of treating schizophrenia: Comparison of two studies done a decade apart. Psychiatry Res. 2014;215(3):547-53. 2. Shearer J, Byford S. The basics of economic evaluation in mental healthcare. BJPsych Adv. 2015 Sep 2;21(5):345-53.

3. Zweifel P. The triple challenge of mental health. European Journal of Health Economics. 2017; Editorial.

-1 EUR $=4.5681$ RON - mean value for 2017, National Bank of Romania 